\title{
СИГНАЛЫ СИНХРОНИЗАЦИИ В ИЗМЕНЕНИЯХ ХИМИЧЕСКОГО СОСТАВА ПОЗДЕМНЫХ ВОД КАМЧАТКИ В СВЯЗИ С СИЛЬНЫМИ ( $\left.M_{\mathrm{w}} \geq 6.6\right)$ ЗЕМЛЕТРЯСЕНИЯМИ
}

\author{
(C) 2013 г. Г. Н. Копылова, Л. Н. Таранова \\ Камчатский филиал Геофизической службы РАН, г. Петропавловск-Камчатский \\ Поступила в редакцию 25.07.2012 г.
}

\begin{abstract}
Рассматриваются результаты применения статистического анализа с использованием методов главных компонент и канонических когерентностей для обработки многолетних (1986-2005 гг.) данных гидрогеохимических наблюдений на самоизливающихся скважинах и источниках Камчатки. Построены частотно-временны́е диаграммы эволюции информативных статистик, характеризующих коллективное поведение многомерных рядов гидрогеохимических данных, и выделены временны́е интервалы и частотные полосы проявления сигналов синхронизации [Любушин, 2007]. Рассмотрены особенности их проявления в сопоставлении с сильными $\left(M_{\mathrm{w}}=6.6-7.8\right)$ местными землетрясениями. Обнаружено, что в изменениях отдельных многомерных рядов такие сигналы могут проявляться как после землетрясений, так и им предшествовать, т.е. они имеют предвестниковый (П2) и постсейсмический (П3) характер.
\end{abstract}

DOI: $10.7868 / \mathrm{S} 0002333713040066$

\section{ВВЕДЕНИЕ}

Изучение предвестников землетрясений и осуществление на их основе среднесрочного сейсмического прогноза являются важнейшими задачами при проведении комплексных геофизических, геохимических и деформометрических наблюдений в сейсмоактивных регионах [Соболев, 1993]. В результате таких наблюдений создаются временные ряды различных параметров электромагнитного и других полей Земли, режима подземных вод, деформометрических измерений, в изменениях которых могут диагностироваться признаки подготовки сейсмической катастрофы. Но, несмотря на многолетние исследования в данном направлении, вопросы выделения, систематизации и оценки достоверности различных видов предвестников землетрясений, а также разработка принципов формулировки решающих правил (т.е., когда нужно объявлять “тревогу”), составляют, в основном, предмет научных дискуссий.

В Камчатском регионе для среднесрочной оценки сейсмической опасности с временем упреждения от первых лет до месяцев-недель используется, главным образом, экспертный анализ данных наблюдений [Чебров и др., 2011]. Основными элементами экспертного анализа являются регулярные заключения по отдельным видам наблюдений с использованием текущих данных о проявлениях отдельных видов предвестников и их сопоставления с ретроспективным опытом наблюдения таких эффектов в связи с землетрясениями. По данным [Копылова, Серафимова, 2009; Серафимова, Копылова, 2010; Чебров и др.,
2011] на Камчатке предвестники по отдельным видам наблюдений и их комплексу возникают в течение недель-месяцев перед землетрясениями с величинами магнитуд не менее 6-7 на расстояниях в первые сотни км.

Проведение гидрогеохимических наблюдений за составом подземных вод и газов является одним из методов поиска предвестников землетрясений. На Камчатке такие наблюдения проводятся Камчатским филиалом Геофизической службы РАН (КФ ГС РАН) на сети самоизливающихся скважин и источников [Копылова и др., 1994; Хаткевич, Рябинин, 2004]. В результате этих работ получены многолетние временны́е ряды данных наблюдений за изменениями концентраций растворенных минеральных вешеств и газов в составе изливающейся на поверхность подземной воды с периодичностью один раз в 3 сут. Такие ряды, относящиеся к каждому отдельному режимному водопроявлению, являются многомерными, так как включают данные аналитического определения основных катионов и анионов, растворенных газов, недиссоциированных молекул, таких как борная и кремниевая кислоты, а также физико-химических показателей - дебитов самоизлива, температуры воды и рН. Поэтому число получаемых временны́х рядов для одного водопроявления может достигать первых десятков (10-20).

На основе визуального анализа в изменениях некоторых временны́х рядов данных гидрогеохимических наблюдений были ретроспективно выделены аномальные вариации в связи с рядом сильных местных землетрясений [Копылова и 
др., 1994; Хаткевич, Рябинин, 2004; Копылова, 2010]. По времени проявления относительно моментов землетрясений с величинами магнитуд порядка 7 и более такие аномалии разделяются на гидрогеохимические предвестники и постсейсмические эффекты. Предвестниковые вариации проявлялись в связи с Камчатскими землетрясениями 6 октября 1987 г., $M_{\mathrm{w}}=6.6,2$ марта 1992 г. $M_{\mathrm{w}}=6.9$ в скважине ГК-1 в изменениях концентрации хлор-иона и в изменениях концентраций гидрокарбонат-иона, сульфат-иона, натрия и кальция в воде скважины Морозная-1 [Копылова и др., 1994; Копылова, Болдина, 2012]. В то же время в изменениях ряда других гидрогеохимических показателей состава подземных вод предвестниковые вариации перед этими землетрясениями не были выявлены, либо они были выражены значительно слабее. Мы полагаем, что основной причиной этого является невысокая точность аналитического определения большей части компонентов состава подземных вод и, соответственно, невозможность выделения "полезного сигнала" из шумовых вариаций отдельных одномерных рядов методом визуального анализа.

Применение статистического метода для обработки многомерных временны́х рядов с использованием оценок максимальных собственных чисел спектральных матриц и статистик канонических когерентностей в скользящем временно́м окне [Любушин, 1993; 1994; 1998; 2007] направлено на выделение наиболее характерных особенностей в совместных изменениях комплекса параметров, в частности, гидрогеохимических данных. Предлагаемый метод является способом уменьшения размерности многомерных данных, к которым относятся гидрогеохимические данные, и может давать качественно новую форму их представления в виде частотно-временны́х диаграмм эволюции информативных статистик при привычном экспертном подходе к прогнозированию землетрясений.

Построение частотно-временны́х диаграмм эволюции информативных статистик, характеризующих наиболее общие особенности поведения многомерных рядов гидрогеохимических данных, позволяет по увеличению их амплитуд выделять сигналы синхронизации [Любушин, 2007], а также оценивать интервалы времени и частотные полосы их проявления. Сигналы синхронизации являются формализованными (информационноматематическими) образами увеличения согласованности в совместных изменениях отдельных временны́х рядов данных гидрогеохимических наблюдений и могут служить признаками повышения уровня их “взаимодействия” на стадиях подготовки сильных землетрясений.

В работах [Любушин и др., 1996; 1998; Любушин, 1998] для периода наблюдений 1986-1992 гг. продемонстрирована эффективность использо- вания аппарата главных компонент и канонических когерентностей для выделения сигналов синхронизации в изменениях многомерных рядов гидрогеохимических данных на стадиях подготовки Камчатских землетрясений 1987 и 1992 гг. с величинами магнитуд 6.6 и 6.9. В связи с этими землетрясениями были обнаружены три вида сигналов синхронизации, которые по времени проявления относительно моментов землетрясений разделялись на предвестниковые (П2) и постсейсмические (П3) эффекты. Кроме этого, в изменениях некоторых многомерных рядов был также выявлен сигнал синхронизации, соответствующий последовательному проявлению предвестника и постсейсмических изменений $(П 2+\Pi 3)$. По сути, сигналы синхронизации вида П2 в изменениях комплекса гидрогеохимических показателей следует рассматривать в качестве нового синтетического вида гидрогеохимического предвестника, который может использоваться в практике прогнозирования землетрясений при условии оценки его достоверности и сейсмопрогностической эффективности.

В 1992-1999 гг. на Камчатке наблюдалось усиление сейсмической активности, произошли 8 землетрясений с $M_{\mathrm{w}}=6.9-7.8$, в том числе сильнейшее Кроноцкое землетрясение 5 декабря 1997 г. $M_{\text {w }}=7.8$, перед которым проявлялись среднесрочные предвестники в изменениях сейсмологических, деформационных и гидрогеологических параметров [Копылова, Серафимова, 2009; Серафимова, Копылова, 2010]. Поэтому ретроспективная оценка проявлений сигналов синхронизации в изменениях многомерных рядов гидрогеохимических данных за многолетний период, включающий несколько сильных сейсмических событий, имеет определенный интерес для развития методики обработки и интерпретации данных гидрогеохимических наблюдений в целях обнаружения предвестников сильных землетрясений Камчатки.

В настоящей работе представлены результаты обработки данных наблюдений за изменениями концентраций хлор-иона $\left(\mathrm{Cl}^{-}\right)$, гидрокарбонатиона $\left(\mathrm{HCO}_{3}^{-}\right)$и растворенной кремниевой кислоты $\left(\mathrm{H}_{4} \mathrm{SiO}_{4}\right)$ в воде скважины ГК-1 (далее ГК1), источников 1 (И1) и 2 (И2) на пункте Пиначево и скважины 1 на пункте Морозная (M1) за 15 лет (1986-2001 гг.). Некоторые из обработанных многомерных рядов имеют длительность 19 лет (с 1986 по 2005 гг.). Характеристика режимных водопроявлений и описание методики наблюдений приводится в [Копылова и др., 1994; Хаткевич, Рябинин, 2004].

Схема расположения наблюдательных пунктов представлена на рис. 1. Здесь же показаны эпицентры 11-ти землетрясений 1987-2004 гг. с $M_{\mathrm{w}}=6.6-7.8$ (табл.). Предполагалось, что подготовка именно этих землетрясений могла прояв- 


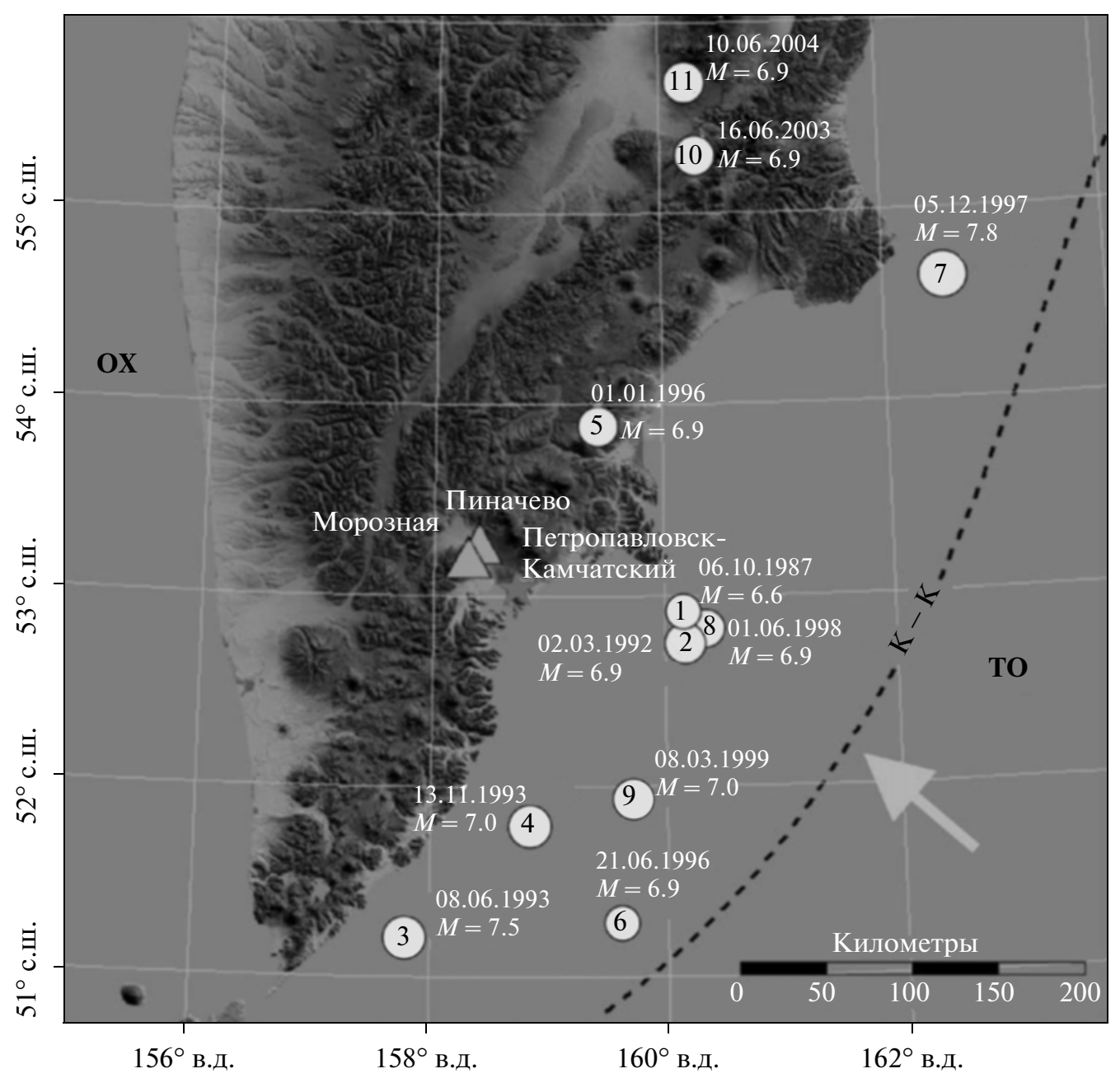

Рис. 1. Схема расположения пунктов наблюдений (треугольники) и эпицентры землетрясений $1987-2004$ гг. с $M_{\mathrm{w}} \geq 6.6$ (кружки). ТО - Тихоокеанская океаническая плита, ОХ - Охотоморская континентальная плита, $\mathrm{K}-\mathrm{K}-\mathrm{Kyрило-}$ Камчатский глубоководный желоб. Стрелкой показано направление движения ТО.

ляться в комплексных изменениях гидрогеохимических параметров режима подземных вод. Дополнительным свидетельством в пользу такого предположения являются зарегистрированные аномалии-предвестники перед этими землетрясениями не только в изменениях отдельных временны́х рядов гидрогеохимических данных, но и в вариациях уровня воды, ряда сейсмологических и деформационных параметров. Особенно яркие аномалии по широкому набору параметров проявлялись перед землетрясениями 1, 2 и 7 [Копылова, Серафимова, 2009; Серафимова, Копылова, 2010].

На рис. 2а представлен кумулятивный график выделения сейсмической энергии при землетрясениях с $M_{\mathrm{w}} \geq 5.0$ на глубинах $0-250$ км в радиусе 400 км от г. Петропавловска-Камчатского. Этот график характеризует сейсмический режим в пределах Камчатской сейсмоактивной области за период времени 1986-2005 гг. На рис. 26 представлено распределение во времени землетрясений с
$M \geq 5.0$. Видно, что рассматриваемые 11 сейсмических событий (рис. 1, табл.) четко выделяются ступеньками на кумулятивном графике (рис. 2a) и именно в результате этих землетрясений было выделено более $90 \%$ энергии упругих сейсмических волн.

Для качественного сравнения интенсивности воздействия отдельных землетрясений на режимные водопроявления в таблице для каждого землетрясения приводится величина отношения $M_{\text {w }} / \lg R$, где $R-$ среднее эпицентральное расстояние до режимных водопроявлений в км.

\section{МЕТОДИКА ОБРАБОТКИ ДАННЫХ}

На рис. 3 приводятся временны́е ряды данных наблюдений на водопроявлениях ГК1, И1, И2, M1 в сопоставлении с моментами землетрясений (табл.). Рассмотрим основные особенности их изменения в периоды сильных землетрясений, которые выявляются при визуальном анализе от- 
Данные о землетрясениях с $M_{\mathrm{w}} \geq 6.6$, произошедших в 1987-2004 гг. (по данным КФ ГС РАН, Геофизической службы PAH, NEIC)

\begin{tabular}{|c|c|c|c|c|c|c|c|c|c|c|c|}
\hline № & $\begin{array}{c}\text { Дата, } \\
\text { ггггммдд }\end{array}$ & $\begin{array}{c}\text { Время, } \\
\text { чч:мм }\end{array}$ & $\begin{array}{l}\text { Широта, } \\
\text { град. с.ш. }\end{array}$ & $\begin{array}{l}\text { Долгота, } \\
\text { град. в.д. }\end{array}$ & $\begin{array}{c}\text { Глубина, } \\
\text { км }\end{array}$ & $\begin{array}{c}\text { Класс, } \\
\text { Ks }\end{array}$ & $\begin{array}{c}\text { Эпицен- } \\
\text { тральное } \\
\text { расстоя- } \\
\text { ние, } R, \text { км }\end{array}$ & $M_{\mathrm{w}}$ & \begin{tabular}{|} 
Баллы \\
пошкале \\
MSK64 в \\
РET
\end{tabular} & $M_{\mathrm{w}} / \lg R$ & $\begin{array}{c}\text { Сутки } \\
\text { от } 4 \text { янв. } \\
1986 \text { г. }\end{array}$ \\
\hline 1 & 19871006 & $20: 12$ & 52.86 & 160.23 & 33 & 14.1 & 130 & 6.6 & $4-5$ & 3.12 & 641 \\
\hline 2 & 19920302 & $12: 30$ & 52.76 & 160.20 & 20 & 14.6 & 130 & 6.9 & $5-6$ & 3.26 & 2250 \\
\hline 3 & 19930608 & $13: 04$ & 51.20 & 157.80 & 40 & 15.0 & 230 & 7.5 & 5 & 3.18 & 2713 \\
\hline 4 & 19931113 & 01:18 & 51.79 & 158.83 & 40 & 14.6 & 160 & 7.0 & $5-6$ & 3.18 & 2871 \\
\hline 5 & 19960101 & 09:58 & 53.88 & 159.44 & 0 & 14.3 & 100 & 6.9 & $4-5$ & 3.45 & 3650 \\
\hline 6 & 19960621 & $13: 57$ & 51.27 & 159.63 & 2 & 13.9 & 230 & 7.0 & $3-5$ & 2.96 & 3822 \\
\hline 7 & 19971205 & $11: 27$ & 54.64 & 162.55 & 10 & 15.5 & 200 & 7.8 & $5-6$ & 3.39 & 4354 \\
\hline 8 & 19980601 & $05: 34$ & 52.81 & 160.37 & 31 & 13.8 & 140 & 6.9 & $4-5$ & 3.22 & 4532 \\
\hline 9 & 19990308 & $12: 26$ & 51.93 & 159.72 & 7 & 14.3 & 170 & 7.0 & $4-6$ & 3.14 & 4812 \\
\hline 10 & 20030616 & $22: 08$ & 55.30 & 160.34 & 190 & 14.7 & 260 & 6.9 & $3-4$ & 2.86 & 6373 \\
\hline 11 & 20040610 & $15: 20$ & 55.68 & 160.25 & 208 & 14.9 & 300 & 6.9 & $3-4$ & 2.78 & 6733 \\
\hline
\end{tabular}

Примечание: РЕТ - г. Петропавловск-Камчатский.

дельных одномерных рядов и описаны ранее в [Копылова и др., 1994; Копылова, Болдина, 2012; Хаткевич, Рябинин, 2004].

В режиме скв. ГК-1 гидрогеосейсмические вариации, т.е. изменения параметров гидрогеологического режима, вызванные подготовкой и реализацией отдельных землетрясений, прослеживаются в противоположных изменениях концентраций хлор-иона (понижение перед землетрясениями и повышение после землетрясений) и гидрокарбонат-иона (понижение перед землетрясениями и повышение после землетрясений). Такие изменения наблюдались в связи с землетрясениями 2-4 и 7. В изменениях концентрации кремниевой кислоты какие-либо закономерные вариации в связи с землетрясениями не выявляются.

Наиболее примечательными особенностями режима источников 1 и 2 являются плавные повышения концентраций хлор-иона и гидрокарбонат-иона после сильных землетрясений с последующим длительным понижением. В изменениях концентрации кремниевой кислоты постсейсмические эффекты менее характерны.

В режиме скв. М-1 гидрогеосейсмические вариации, предшествующие и сопутствующие землетрясениям 1-5, проявлялись в понижениях

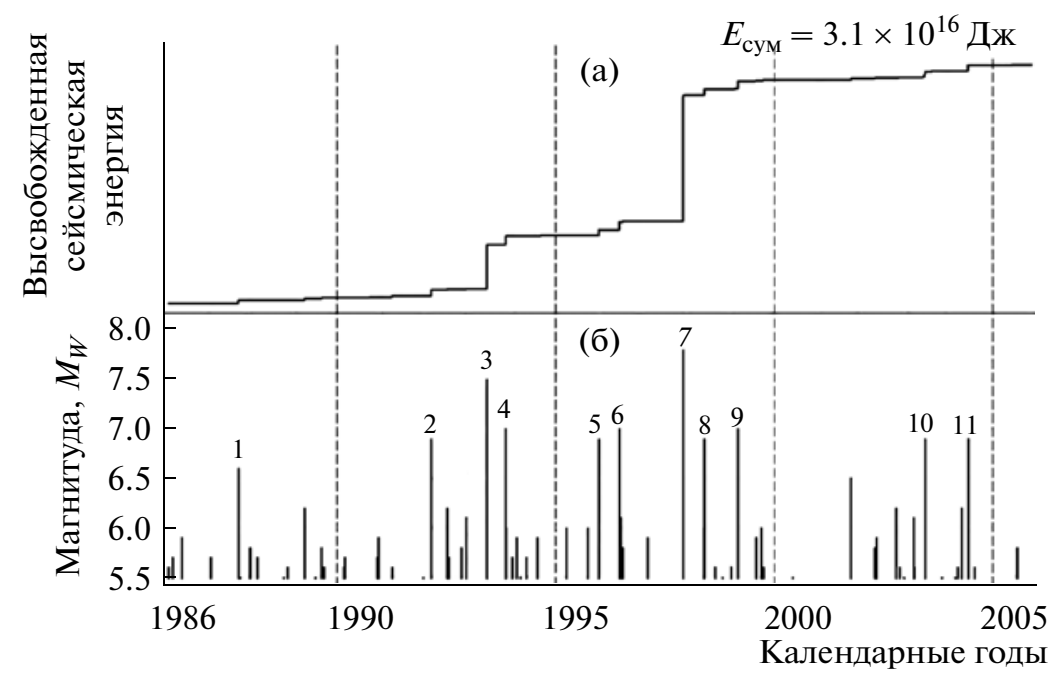

Рис. 2. Характеристика сейсмического режима Камчатки в 1986-2005 гг:: (а) - кумулятивный график выделения сейсмической энергии при землетрясениях с $M_{\mathrm{w}} \geq 5.0$, произошедших в радиусе 400 км от г. Петропавловска-Камчатского (координаты $53.0^{\circ}$ с.ш., $158.6^{\circ}$ в.д.) на глубинах от 0 до 250 км; (б) - распределение во времени моментов землетрясений с $M_{\mathrm{w}} \geq 5.0$ : номера землетрясений соответствуют номерам в таблице и на рис. 1. 

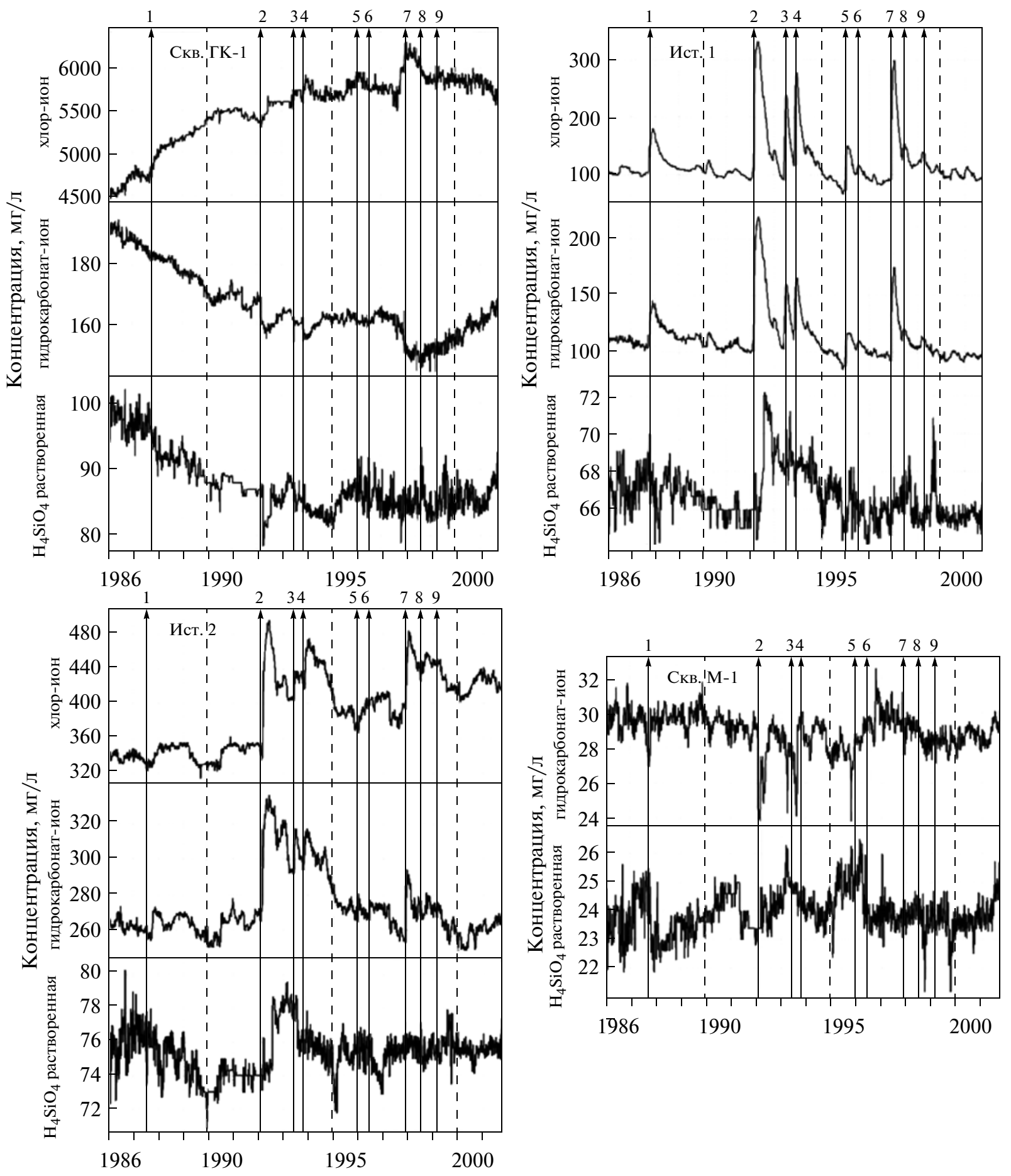

Рис. 3. Изменение параметров гидрогеохимического режима скважин и источников в 1986-2001 гг. в сопоставлении с моментами землетрясений: номера землетрясений соответствуют номерам в табл. и на рис. 1 , рис. 2.

концентрации гидрокарбонат-иона. В изменениях концентрации кремниевой кислоты закономерные вариации в связи с сильными землетрясениями не прослеживаются.

Результаты визуального анализа исходных данных показывает, что изменения отдельных временны́х рядов в периоды, предшествующие и сопутствующие сильным землетрясениям, весьма индивидуальны и специфичны для каждого режимного водопроявления. Исключение составляют только закономерные постсейсмические эффекты в изменениях концентраций хлор-иона и гидрокарбонат-иона в воде источников 1 и 2. Такие особенности формирования гидрогеохи- 
мического режима подземных вод создают определенные сложности при интерпретации отдельных временных рядов данных гидрогеохимических наблюдений с целью выделения признаков подготовки сильных землетрясений.

Представленные на рис. 3 ряды использовались для формирования 8-ми многомерных рядов гидрогеохимических данных, каждый из которых включал не менее трех одномерных временны́ рядов $(n \geq 3$, где $n-$ число одномерных временны́х рядов, образовывающих многомерный ряд).

Всю совокупность полученных многомерных ряды можно разделить на три группы (I-III).

Группу I составляют многомерные ряды, образованные из одномерных рядов гидрогеохимических данных по отдельным водопроявлениям. Для источников И1, И2 и скважины ГК1 было сформировано по одному 3-мерному ряду: И1_3, И2 3, ГК1 3.

В группу II многомерных рядов включены данные по отдельным гидрогеохимическим параметрам, измеряемым на нескольких $(n \geq 3)$ водопроявлениях. Каждый компонент состава подземной воды характеризуется индивидуальной точностью аналитического определения концентрации [Хаткевич, Рябинин, 2004] и, как показано выше, специфическими особенностями изменения для различных водопроявлений в связи с землетрясениями. Поэтому анализ трех многомерных рядов группы II (Cl_3, HCO3_4 и H4SiO4_4) направлен на оценку информативности различных гидрогеохимических параметров и на прослеживание особенностей их коллективного поведения в связи с землетрясениями.

В группу III включены ряды концентраций различных компонентов состава воды из нескольких водопроявлений. Например, данные наблюдений на водопроявлениях станции Пиначево ГК1, И1, И2 образовывают 9-тимерный ряд (III 9); данные наблюдений на водопроявлениях ГК $\overline{1}, \mathrm{M} 1$, И1, И2 - 11-тимерный ряд (III_11) (рис. 3).

Для каждого исходного временно́го ряда (рис. 3) предварительно осуществлялся переход к первым разностям для подавления трендов и интенсивных низкочастотных составляющих в их изменениях [Любушин, 1993; 2007; Любушин и др., 1996; 1997].

Трехсуточный интервал дискретизации данных позволяет рассматривать вариации гидрогеохимических параметров на частотах от $1 / 6$ сут $^{-1}=$ $=0.167$ сут $^{-1}$ до $1 / L$, где $L-$ длина скользящего временно́го окна. Анализируемый диапазон частот выбирался от $1 / 6 \mathrm{cyT}^{-1}$ до $5 / L \mathrm{cyT}^{-1}$, чтобы наиболее низкочастотные вариации укладывались не менее пяти раз по длине скользящего окна. Принимая длину окна $L$ в 100 и 200 отсчетов или 300 и 600 сут, получаем рассматриваемый диапазон частот от $1 / 6$ до $1 / 60$ и $1 / 120$ сут $^{-1}$ (0.1667-0.0167 сут ${ }^{-1}$ и $0.1667-0.0083$ сут $\left.^{-1}\right)$.
Большая часть обнаруженных ранее гидрогеохимических предвестников имели продолжительность от первых месяцев до 7-9 мес. [Копылова, 2010; Копылова и др., 1994; Хаткевич, Рябинин, 2004]. Примерно такой же порядок продолжительностей имеют и постсейсмические вариации. Поэтому выбор окна в 100 и 200 отсчетов (300 и 600 сут) и шага в 10-20 отсчетов (30-60 сут) представляется достаточно обоснованным с точки зрения обнаружения относительно "высокочастотных” сигналов синхронизации в комплексных изменениях химического состава подземных вод.

В соответствии с математическими алгоритмами, приведенными в [Любушин, 1993; 1998; 2007], производился расчет и построение частотно-временны́х диаграмм эволюции трех статистик:

- максимального собственного числа спектральной матрицы $\lambda_{1}(\tau, \omega)$, где $\tau-$ правый край скользящего временно́го окна, $\omega$ - частота;

- суммы квадратов покомпонентных канонических когерентностей $\rho^{2}(\tau, \omega)$,

- произведения покомпонентных канонических когерентностей $\kappa(\tau, \omega)$.

С вычислительной точки зрения величина $\lambda_{1}(\tau, \omega)$ представляет спектр мощности первой главной компоненты многомерного ряда, т.е. некоторого скалярного временно́го ряда, получаемого операцией линейной фильтрации многомерного ряда и который несет в себе максимум информации о совместном (синхронном) поведении составляющих его (многомерный ряд) компонент [Любушин, 1994]. Особенностью функции $\lambda_{1}(\tau, \omega)$ является ее реагирование на наличие компонент многомерного ряда, которые имеют наиболее сильные амплитудные вариации в рассматриваемых диапазонах частот $\omega$ и времен $\tau$.

При расчетах статистик $\rho^{2}(\tau, \omega)$ и $\kappa(\tau, \omega)$ (их величины изменяются в диапазоне от 0 до 1) использовался аппарат построения канонических когерентностей многомерного ряда в скользящем временно́м окне [Любушин, 1998], который является альтернативным способом выделения сигналов синхронизации, по сравнению с методом главных компонент.

Частотно-зависимые меры покомпонентных канонических когерентностей $v_{1}(\tau, \omega), v_{2}(\tau, \omega)$, $\ldots, v_{l}(\tau, \omega)$, где $1,2, \ldots, l-$ номера скалярных временны́х рядов, составляющих $l$-мерный временно́й ряд, описывают степень связности соответствующих скалярных компонент многомерного ряда со всеми остальными. Функция

$$
\kappa(\tau, \omega)=v_{1}(\tau, \omega) v_{2}(\tau, \omega) \cdot \ldots \cdot v_{l}(\tau, \omega),
$$

как показатель степени коллективности поведения комплекса рассматриваемых параметров, очень требовательна к качеству временны́х рядов, составляющих многомерный ряд. Ее отличие от нуля означает, что на данной частоте и в данном временно́м диапазоне все компоненты много- 
мерного ряда должны быть достаточно сильно связаны друг с другом, т.е. все определенные величины $v_{i}(\tau, \omega)$ значимо отличаются от нуля. В противном случае, при величине одного из сомножителей в (1) близкой к нулю, значение к( $\tau$, $\omega)$ будет сильно уменьшаться.

Функция

$$
\rho^{2}(\tau, \omega)=\sum_{i=1}^{l} v_{i}^{2}(\tau, \omega) / l
$$

является более устойчивой к включению в число анализируемых рядов малоинформативных компонентов. Следует также отметить, что функции $\rho^{2}(\tau, \omega)$ и к $(\tau, \omega)$ по своему построению зависят, главным образом, от соотношения между фазами компонентов многомерного ряда. Поэтому анализ их распределения в частотно-временно́й области позволяет диагностировать “скрытые” сигналы синхронизации [Любушин, 1998].

При построении спектральных матриц многомерных временны́х рядов использовалась параметрическая модель векторной авторегрессии 3его порядка ( $p=3)$, которая подбиралась эмпирическим путем перебора моделей и является оптимальной.

\section{РЕЗУЛЬТАТЫ И ИХ ОБСУЖДЕНИЕ}

На рис. 4 и рис. 5 приводятся примеры частотно-временны́ диаграмм эволюции расчетных статистик для многомерных рядов групп I-III. Сигналы синхронизации фиксируются на диаграммах в виде “темных" пятен, соответствующих увеличению амплитуд статистик $\lambda_{1}(\tau, \omega)$, $\rho^{2}(\tau, \omega)$ и $\kappa(\tau, \omega)$ не менее $50 \%$ от их максимальных величин.

Ряды группы I. В поведении рядов И1_3 (рис. 4a) и И2_3 выделяются сигналы, соответствующие, в основном, постсейсмическим эффектам П3. Они проявляются преимущественно на периодах $\geq 20-$ 40 сут.

В изменении ряда ГК1_3 (рис. 5в) прослеживаются длительные сигналы в 1986-1991 гг., 19961997 гг. и в 1999 г. на периодах 15-30 сут. Их можно отнести к эффекту последовательного проявления предвестниковых и постсейсмических сигналов П2 + П3 от землетрясений 1, 5-8 и 9. Перед землетрясениями 1-3, 5, 7 и 9 также выделяются локальные максимумы статистик, фиксирующие, по-видимому, относительно краткосрочные стадии предвестниковых эффектов.

Ряды группы II. В изменениях многомерных рядов Cl_3 (рис. 4в) и НCO3_4 (рис. 5а) выделяются два вида сигналов синхронизации: постсейсмические низкочастотные на периодах $\geq 30$ сут (П3) и относительно “высокочастотные” на периодах 15-25 сут во временны́х окнах, включаю- щих наиболее сильные землетрясения 1-4 и 7. При этом “высокочастотные” сигналы имеют характер последовательного наложения предвестниковых и постсейсмических эффектов П2 + П3. Например, в изменениях ряда $\mathrm{HCO}_{2} 4$ (рис. 5а) интенсивный сигнал П2 предшествовал в течение ста суток моменту Кроноцкого землетрясения 5 декабря 1997 г., $M=7.8$ (№ 7 в табл.), а после его реализации сменился длительным постсейсмическим сигналом П3, который смещен в низкочастотную область.

На диаграмме H4SiO4_4 (рис. 5б) фиксируются три длительных постсейсмических сигнала П3 после землетрясений 1, 2, 7 .

Ряды группы III. Частотно-временны́е диаграммы эволюции статистик $\lambda_{1}(\tau, \omega), \rho^{2}(\tau, \omega)$ и $\kappa(\tau, \omega)$ для двух многомерных рядов группы III (пример см. на рис. 4б) оказались наименее информативными, так как на них фиксируется множество слабовыраженных сигналов синхронизации, которые сложно классифицировать по времени проявления относительно рассматриваемых землетрясений. Это может быть обусловлено повышенным уровнем шума в многомерных рядах, сформированных из большого числа скалярных рядов различных компонентов состава подземных вод. Такая неоднозначность в проявлении сигналов синхронизации в изменениях многомерных рядов, сформированных из большого числа одномерных рядов гидрогеохимических данных, также может быть обусловлена индивидуальными особенностями проявления предвестниковых и постсейсмических процессов в различных водопроявлениях [Копылова, 2010].

Особенности проявления сигналов синхронизаиии П2 и ПЗ в изменениях многомерных рядов групп I u II. Выделяемые на диаграммах сигналы синхронизации типа П2 имеют длительности от первых десятков суток до 100-150 суток (в среднем, 1-3 мес.) и проявляются на периодах от 15 до 30 сут. Постсейсмические сигналы П3 имеют большую продолжительность, достигающую 500 и более суток и проявляются в более низкочастотной области на периодах от 20 до 60-120 сут. Возможно, что сигналы синхронизации П3 могут иметь и большие продолжительности на периодах, превышающих 60-120 сут. Но такая частотно-временна́я область проявления сигналов синхронизации в изменениях гидрогеохимических данных не рассматривается в настоящей работе.

Рассмотрим, насколько устойчивой является связь между сигналами синхронизации П2 и последующими сильными землетрясениями (табл.). В качестве параметра, характеризующего такую связь, использовалась величина

$$
P=m / n,
$$

где $m$ - число землетрясений, перед которыми на диаграммах диагностировались сигналы синхро- 
(a)

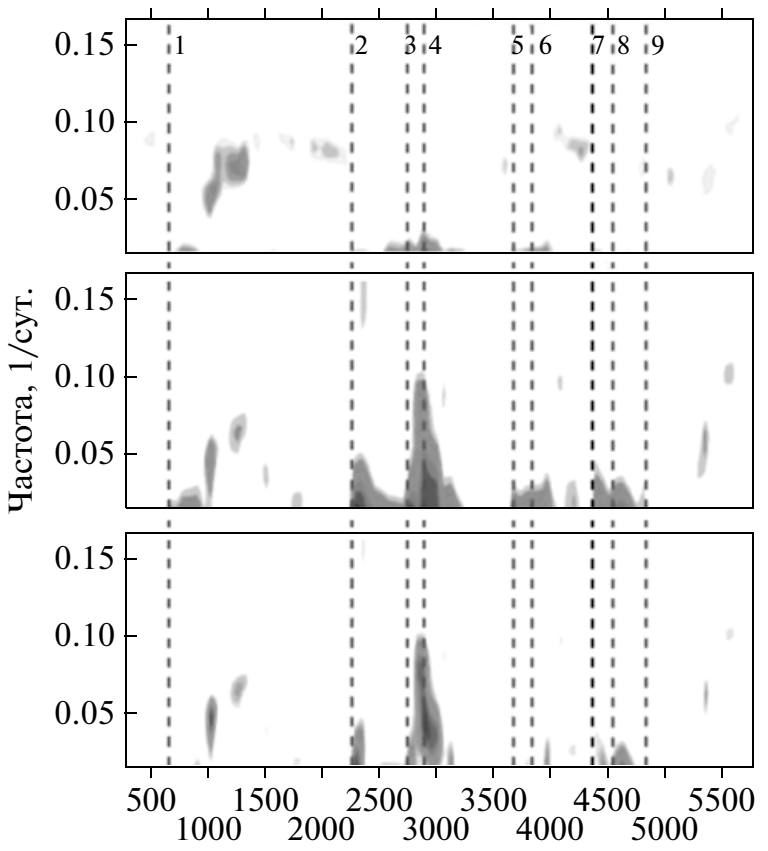

Время в сут. 04.03.1986-15.10.2001 гг.
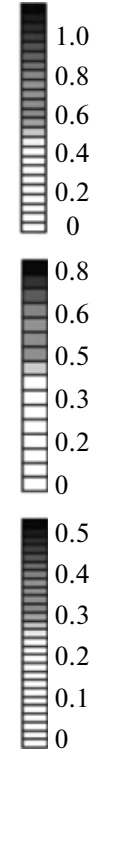

(б)

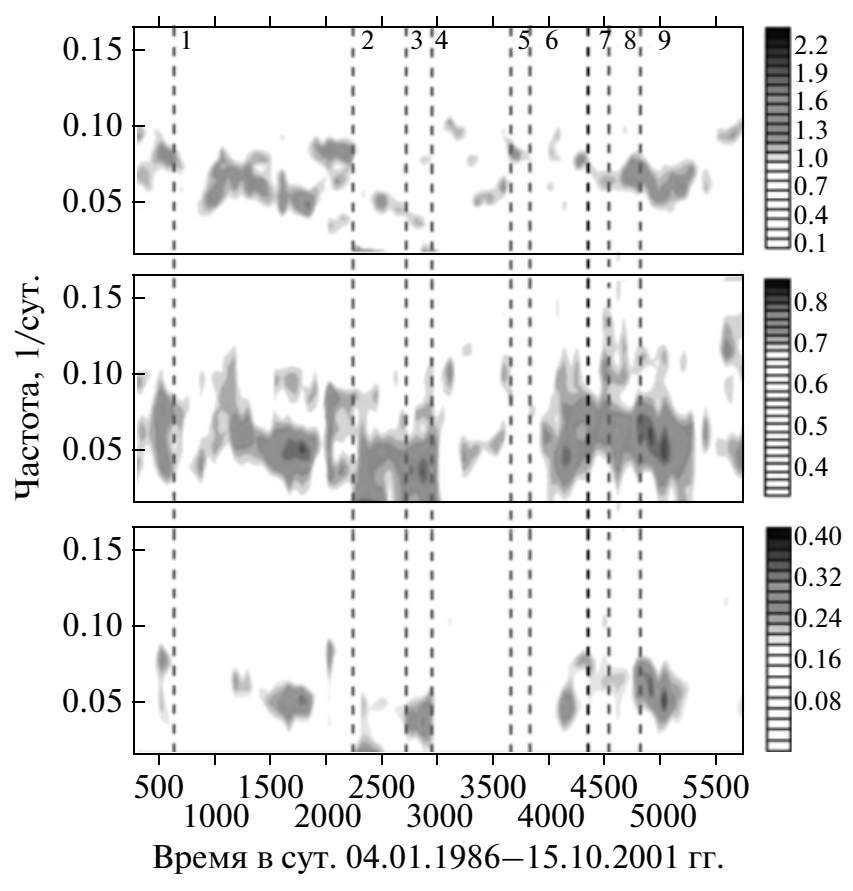

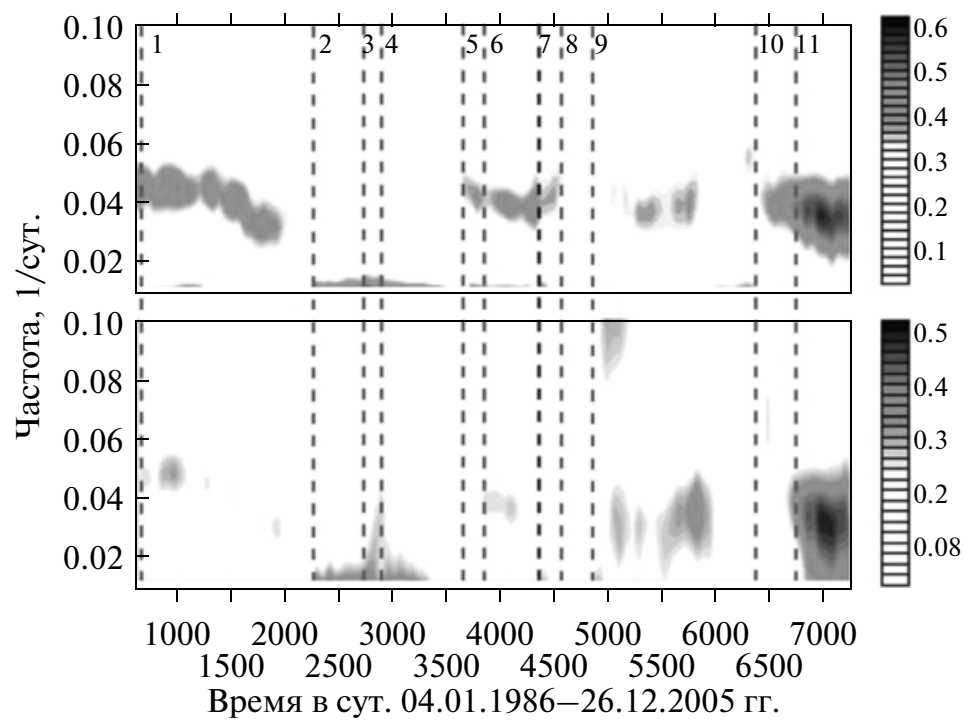

Рис. 4. Примеры частотно-временны́х диаграмм эволюции статистик, характеризующих степень коллективности поведения многомерных временны́х рядов данных гидрогеохимических наблюдений (I-III группы) в сопоставлении с землетрясениями (показаны вертикальными пунктирными линиями, номера землетрясений соответствуют рис. 1рис. 2 и табл.): (а) - I-И1_3 - 3-мерный ряд данных наблюдений на источнике 1, окно 300 сут, шаг 60 сут: сверху вниз $\lambda_{1}(\tau, \omega), \rho^{2}(\tau, \omega), \kappa(\tau, \omega)$; (б) - III-11-мерный ряд наблюдений за концентрациями $\mathrm{Cl}^{-}, \mathrm{HCO}_{3}^{-}, \mathrm{H}_{4} \mathrm{SiO}_{4}$ в воде водопроявления ГК1, И1, И2, М1; окно 300 сут, шаг 60 сут: сверху вниз $\lambda_{1}(\tau, \omega), \rho^{2}(\tau, \omega), \kappa(\tau, \omega)$; (в) - II-Cl_3, окно 600 сут, шаг 60 сут: сверху вниз $\lambda_{1}(\tau, \omega), \rho^{2}(\tau, \omega)$.

низации; $n$ - общее число произошедших землетрясений за время наблюдений.

Для многомерных рядов групп I и II получены оценки $P$ от 0.4 до 0.7 . Такие величины $P$ соответствуют оценкам для наиболее информативных гидрогеохимических показателей, таких как, из- менение концентрации хлор-иона в воде скв. ГК-1 (рис. $3, P=6 / 9=0.67$ ) и согласуются с оценкам величин $P$ по другим методам наблюдений - сейсмологическим, геодезическим и гидрогеологическим ( $P=0.38-0.75$, см. табл. 4 в [Копылова, Серафимова, 2009]). 
(a)

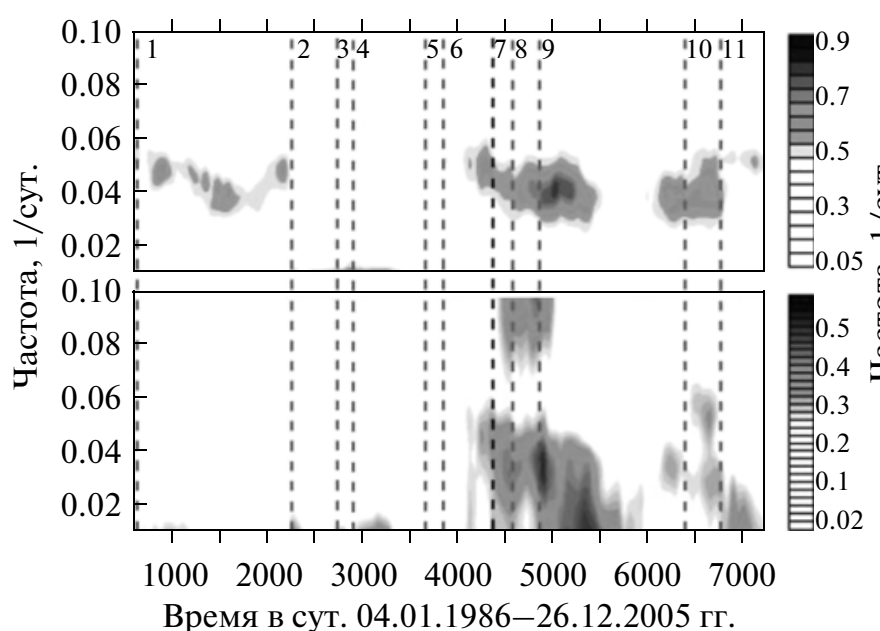

(б)

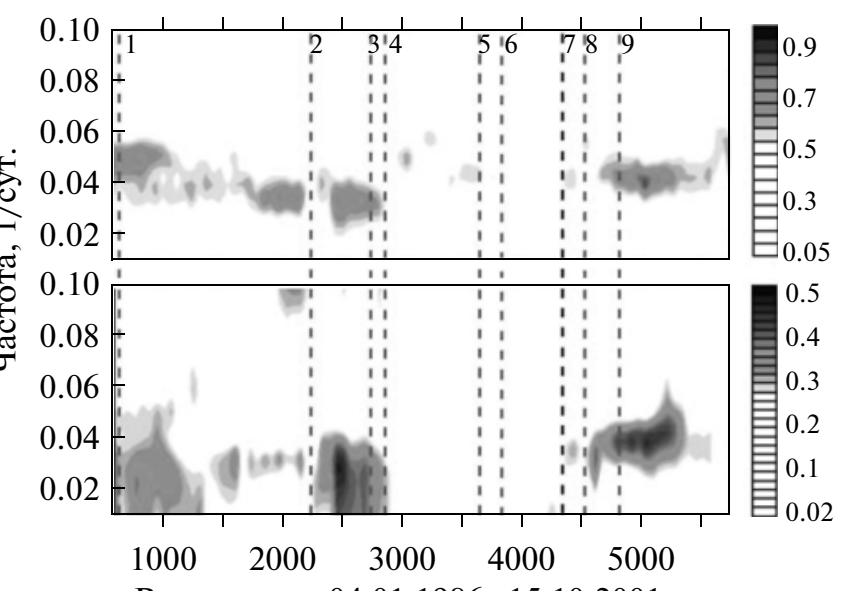

Время в сут. 04.01.1986-15.10.2001 гг.

(в)

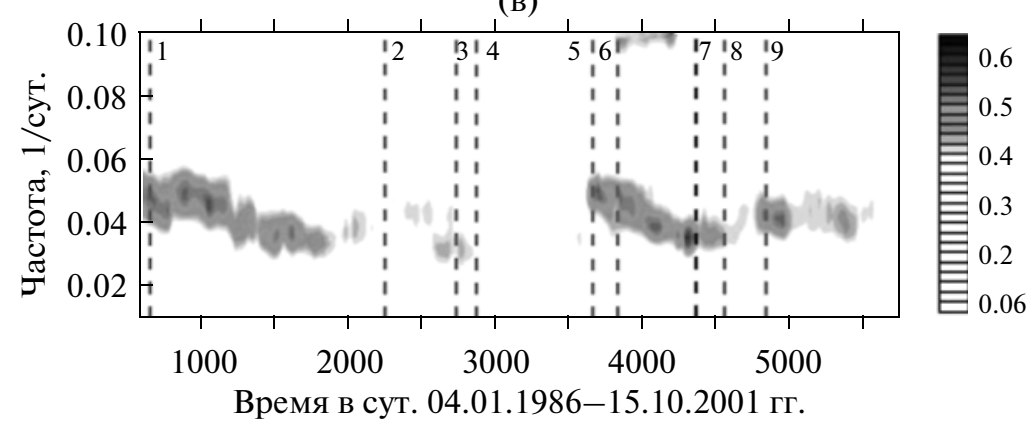

Рис. 5. Частотно-временны́е диаграммы эволюции статистик, характеризующих степень коллективности поведения многомерных временны́х рядов данных гидрогеохимических наблюдений: (а) - II-HCO3_4, сверху вниз $\lambda_{1}(\tau, \omega), \rho^{2}(\tau$, $\omega)$, окно 600 сут, шаг 60 сут; (б) - II-H4SiO4_4, сверху вниз $\lambda_{1}(\tau, \omega), \rho^{2}(\tau, \omega)$, окно 600 сут, шаг 60 сут; (в) - I-ГK1_3, $\lambda_{1}(\tau, \omega)$, окно 600 сут, шаг 30 сут.

Существенным недостатком сигналов синхронизации типа П2 в качестве среднесрочного предвестника сильных землетрясений Камчатки является сложность или даже невозможность их выделения на фоне развития постсейсмических сигналов П3 от предыдущих землетрясений, если оба сигнала развиваются в близких диапазонах частот. Вместе с тем, как показывает опыт, их разделение возможно на основе детального анализа частотно-временны́х диаграмм эволюции всех трех статистик $\lambda_{1}(\tau, \omega), \rho^{2}(\tau, \omega)$ и $\kappa(\tau, \omega)$, построенных в различных скользящих окнах (например, 300 и 600 сут) и с различным смещением (например, 60 и 30 сут). При уменьшении длины скользящего окна и его сдвига по времени наблюдается тенденция смещения сигнала П2 в более высокочастотную область.

\section{ЗАКЛЮЧЕНИЕ}

Результаты анализа рассмотренных многомерных рядов многолетних данных гидрогеохимических наблюдений в сопоставлении с сильными $(M \geq 6.6)$ землетрясениями позволяют сформули- ровать предварительные выводы относительно перспектив применения методики многомерного анализа для обработки гидрогеохимических данных с целью выявления сигналов синхронизации в их изменениях.

1. Сигналы синхронизации в связи с землетрясениями проявляются, в основном, в изменениях многомерных рядов, включающих совокупность одномерных рядов гидрогеохимических данных по одному водопроявлению (группа I) или по отдельному параметру (группа II). При этом использование всех трех статистик $\lambda_{1}(\tau, \omega), \rho^{2}(\tau, \omega)$, $\kappa(\tau, \omega)$ дает однозначный результат при выделении таких сигналов.

В изменениях рядов И1_3 и И2_3 (группа I) проявляются, в основном, низкочастотные постсейсмические сигналы синхронизации П3 на периодах $\geq 20-40$ сут. В изменениях ряда ГК1_3 (рис. 5в) выделяются сигналы синхронизации на периодах 15-30 сут в 1986-1991 гг., 1996-1997 гг. и в 1999 г., которые можно рассматривать как последовательное проявление предвестниковых и постсейсмических эффектов (сигналы вида П2 + + П3) в связи с землетрясениями $1,5-8$ и 9. Перед 
землетрясениями 1-3, 5, 7 и 9 выделяются локальные максимумы статистик, фиксирующие, по-видимому, относительно краткосрочную стадию предвестникового эффекта синхронизации П2. Таким образом, перед шестью сильными землетрясениями 1986-2001 гг. из 9-ти произошедших (или в 67\% случаев) проявлялись сигналы синхронизации в изменениях многомерного ряда ГK1_3.

В изменениях многомерных рядов Cl_3 (рис. 4в) и HCO3_4 (рис. 5а) (группа II) выделяются два вида сигналов синхронизации: постсейсмические низкочастотные П3 на периодах $\geq 30$ сут и относительно “высокочастотные" на периодах 15-25 сут. “Высокочастотные” сигналы имеют характер последовательного наложения предвестниковых и постсейсмических эффектов и соответствуют виду П2 + П3. В частности, интенсивный сигнал синхронизации П2+П3 начал проявляться в изменениях ряда $\mathrm{HCO} 344$ за сто суток перед Кроноцким землетрясением 5 декабря 1997 г., $M=7.8$ (рис. 5a).

В изменениях ряда $\mathrm{H} 4 \mathrm{SiO} 44$ (рис. 5б) выделяются три продолжительных постсейсмических сигнала синхронизации П3, смещенных по времени относительно землетрясений 1, 2 и 7. Указанные землетрясения характеризуются интенсивным воздействием на пункты наблюдений (табл.). Выявленные сигналы в поведении ряда H4SiO4_4 показывают, что постсейсмические изменения концентраций кремниевой кислоты имеют, в основном, “скрытый” характер и проявляются с запаздыванием, по сравнению с постсейсмическими изменениями концентраций хлор-иона и гидрокарбонат-иона.

Наименее информативными для поиска сигналов синхронизации являются многомерные ряды группы III. Это связано с повышенным уровнем шумовых компонент в таких рядах вследствие различия точностей аналитического определения отдельных компонентов состава воды, а также вследствие локальных особенностей формирования гидрогеосейсмических эффектов в различных водопроявлениях.

2. Рассмотренная методика диагностики сигналов синхронизации в изменениях многомерных рядов гидрогеохимических данных является полезной и характеризуется достаточной сейсмопрогностической эффективностью. На это указывает оценка связи сигналов синхронизации вида П2 с последующими сильными землетрясениями $(P=0.4-0.7)$, а также сравнение этого вида предвестника с другими среднесрочными предвестниками, используемыми уже в настоящее время для сейсмического прогноза на Камчатке, для которых величина Р не превышает 0.75 .

Работа выполнена при поддержке РФФИ, проект 12-05-0014б-а.

\section{СПИСОК ЛИТЕРАТУРЫ}

Копылова (Гриц) Г.Н. Эффекты сейсмичности в режиме подземных вод (на примере Камчатского региона). Автореферат дис. ... доктора геол.-мин. наук. Петропавловск-Камчатский: Камчатский филиал Геофизической службы РАН. 2010. 36 с.

Копылова Г.Н., Болдина С.В. Аномальные изменения химического состава подземных вод в связи с Камчатским землетрясением 02.03.1992 г. $\left(M_{\mathrm{w}}=6.9\right) / /$ Геофизические исследования. 2012. Т. 13. № 1. С. 39-49.

Копылова Г.Н., Серафимова Ю.К. О проявлении некоторых среднесрочных предвестников сильных $\left(M_{\mathrm{w}} \geq 6.6\right)$ землетрясений Камчатки 1987-2004 гг. // Геофизические исследования. 2009. № 4. Т. 10. С. 17-33.

Копылова Г.Н., Сугробов В.М., Хаткевич Ю.М. Особенности изменения режима источников и гидрогеологических скважин Петропавловского полигона (Камчатка) под влиянием землетрясений // Вулканология и сейсмология. 1994. № 2. С. 53-70.

Любушин А.А. Многомерный анализ временны́х рядов систем геофизического мониторинга // Физика Земли. 1993. № 3. С. 103-108.

Любушин А.А. Классификация состояний низкочастотных систем геофизического мониторинга // Физика Земли. 1994. № 7. С. 135-141.

Любушин А.А. Анализ канонических когерентностей в задачах геофизического мониторинга // Физика Земли. 1998. № 1. С. 59-66.

Любушин А.А. Анализ данных систем геофизического и экологического мониторинга. М.: Наука. 2007. 228 с.

Любушин А.А., Копылова Г.Н., Хаткевич Ю.М. Применение многомерного анализа для обработки данных гидрогеологических наблюдений на Петропавловском полигоне, Камчатка, с целью поиска предвестников сильных землетрясений // Вулканология и сейсмология. 1996. № 1. С. 79-97.

Любушин А.А., Копылова Г.Н., Хаткевич Ю.М. Анализ спектральных матриц данных гидрогеологических наблюдений на Петропавловском полигоне, Камчатка, в сопоставлении с сейсмическим режимом // Физика Земли. 1997. № 6. С. 79-89.

Серафимова Ю.К., Копылова Г.Н. Среднесрочные предвестники сильных $(M \geq 6.6)$ землетрясений Камчатки 1987-2007 гг: ретроспективная оценка их информативности для прогноза // Вулканология и сейсмология. 2010. № 4. С. 3-12.

Соболев Г.А. Основы прогноза землетрясений. М.: Наука. 1993. $313 \mathrm{c.}$

Хаткевич Ю.М., Рябинин Г.В. Гидрогеохимические исследования на Камчатке. Комплексные сейсмологические и геофизические исследования Камчатки. Петропавловск-Камчатский: Камчатский печатный двор. 2004. C. 96-112.

Чебров В.Н., Салтыков В.А., Серафимова Ю.К. Прогнозирование землетрясений на Камчатке. По материалам работы Камчатского филиала Российского экспертного совета по прогнозу землетрясений, оценке сейсмической опасности и риска в 1998-2009 гг. М.: Светоч Плюс. 2011. 304 с. 